\title{
Molten salt based nuclear-renewable energy system with thermal storage
}

\author{
G. Maronati \\ Georgia Institute of Technology \\ 770 State Street, Atlanta, GA 30332-0745, USA \\ e-mail: gmaronati@gatech.edu \\ B. Petrovic \\ Georgia Institute of Technology \\ 770 State Street, Atlanta, GA 30332-0745, USA \\ Phone number: +1 (404) 894-8173, e-mail: bojan.petrovic@gatech.edu
}

\begin{abstract}
This paper presents a concept of a Nuclear-Renewables hybrid energy system (NuRenew), originally introduced in 2011 [1-2] and presented at ICREPQ'16 [3]. Extended use of nuclear-renewable hybrid energy systems can help replace fossil fuel-based energy sources with near-zero emission power sources. The NuRenew concept synergistically combines high-temperature salt cooled reactors (SCR), liquid salt based concentrated solar power (CSP), and liquid salt based thermal energy storage (TES), The nuclear power plant (NPP) and a CSP plant are integrated through a common TES system. This dual use of TES improves its usage which increases its capacity factor and effectively lowers its cost. This improves the overall performance of the system and decreases LCOE. This paper evaluates the benefits of the NPP-CSP-TES system coupling as compared to stand-alone configurations.
\end{abstract}

\section{Key words}

Hybrid energy park, process heat, high-temperature nuclear reactor, concentrated solar power, energy storage

\section{Introduction}

Large nuclear reactors are used for base-load production. Production by renewables is intermittent, unpredictable and characterized by high uncertainties, and at times of the day when production by renewables is high, nuclear production is subjected to high penalties. In order to avoid overproduction, a nuclear reactor can be coupled with energy storage that stores surplus energy not requested by the grid. Similarly, to stabilize electricity produced by renewables, energy storage can be used. During the production peaks, energy can be stored and then used at times when there is reduced production or high demand. For a concentrated solar power system (CSP), thermal energy is stored during the day and used during times of the day and night when the grid requirement is higher than the production. The amount of storage needed depends on many variables including the desirable autonomy of the system. For a given day, the amount of storage needed is related to the difference between the energy produced and the grid energy requirement. To satisfy grid requirements and address variations with a longer time periods (days, weeks, moths), the amount of storage needed increases as a consequence of the unpredictability of weather conditions. A series of sunny days followed by a series of cloudy days requires a higher amount of energy to be stored.

\section{LCOE}

The parameter that is often used to describe the economics of an electricity generating plant is the Levelized Cost of Electricity (LCOE), which represents the cost per-kWh produced of building and operating a generating plant over an assumed financial life and duty cycle. The factors that affect the LCOE are the following:

- Total capital investment;

- Operation and Maintenance;

- Fuel;

- Decommissioning;

- Financing.

LCOE was calculated through Eq. 1 [4]. The numerator represents the present value of cost of capital costs (CC), operation and maintenance costs $(O \& M)$, fuel costs $(F)$ and decommissioning costs $(D)$, while the denominator represents the present value of the electricity $(E)$ produced during the lifetime of the generation system. Decommissioning costs were neglected.

$$
L C O E=\frac{\sum_{t} \frac{C C_{t}+O \& M_{t}+F_{t}+D_{t}}{(1+r)^{t}}}{\sum_{t} \frac{E_{t}}{(1+r)^{t}}}
$$

Capital costs for the TES were estimated through scaling laws. TES costs per unit capacity are believed to decrease with the TES capacity, as the tank mass of steel increases less than proportionally with the mass of salt. 
Ref. [5] shows data for a 115 MWe CSP system with 10 hours of storage. The storage, having a molten salt volume of $13,000 \mathrm{~m}^{3}$ and a cost of $27 \$ / \mathrm{kWh}$, was taken as reference. It was assumed that half of O\&M costs are associated with the tower, and the other half with the TES. For the purpose of this study, capital cost and O\&M costs associated with the TES were scaled according to the molten salt tank surface area, which is a good indicator of the steel mass of the tank. Molten salt tanks dimensions were calculated maintaining the same diameter/height ratio from Ref. [6]. Sensitivity of TES cost (per unit capacity) is shown in Fig. 1.

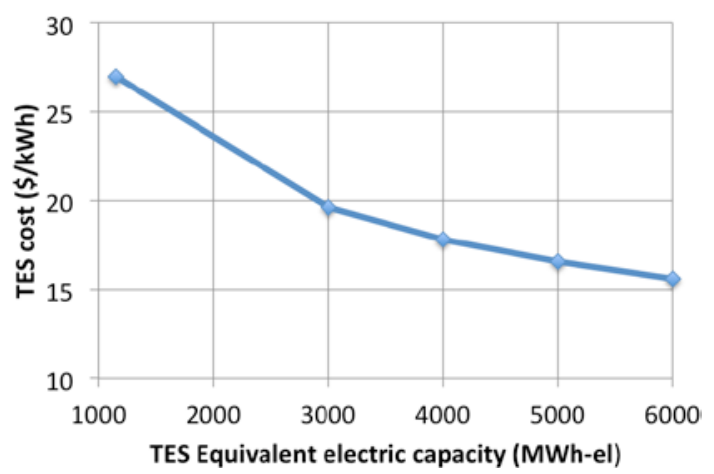

Fig. 1 - TES capital cost - economy of scale

Ref. [7] describes data for a liquid salt cooled reactor, the AHTR, under development at Oak Ridge National Laboratory, which was taken as the reference. The power of the reactor was scaled down from 1,530 MWe to 1,000 MWe.

Table 1. SCR parameters

\begin{tabular}{|c|c|c|}
\hline & SCR & \\
\hline Power & 1000 & MWe \\
\hline Efficiency & 0.45 & - \\
\hline Life [4] & 60 & years \\
\hline Capacity factor [4] & 0.92 & \\
\hline Thermal storage capacity & 3 & hours \\
\hline $\begin{array}{l}\text { Thermal storage equivalent } \\
\text { electric capacity }\end{array}$ & 3,000 & MWhe \\
\hline Storage life [5] & 30 & years \\
\hline Capital costs [4] & 3149 & $\$ / \mathrm{kW}$ \\
\hline O\&M costs [4] & 102.78 & M\$/year \\
\hline Fuel costs [4] & 132 & M\$/year \\
\hline Storage capital cost & $\begin{array}{l}52.26 \\
19.61 \\
\end{array}$ & $\begin{array}{l}\mathrm{k} \$ / \mathrm{m}^{2} \\
\$ / \mathrm{kWh}\end{array}$ \\
\hline Storage O\&M costs & 2.64 & $\begin{array}{l}\$ / \mathrm{m}^{2}- \\
\text { year }\end{array}$ \\
\hline Storage surface area & 2681 & $\mathrm{~m}^{2}$ \\
\hline
\end{tabular}

For this analysis, the SCR was assumed to operate at full power for 21 hours each day. Three hours per day are lost caused by the peek production from the renewables, forcing other power generators to reduce their production. Under this assumption, LCOE was calculated for the SCR with TES and without TES. LCOE values, calculated for a $5 \%$ and $7 \%$ discount rate (r), are shown in Table 2.

Table 2. SCR LCOE values

\begin{tabular}{l|l|l|l|l} 
& $\begin{array}{l}\text { Capacity } \\
\text { factor }\end{array}$ & $\begin{array}{l}\mathrm{LCOE} \\
(\mathrm{r}=5 \%)\end{array}$ & $\begin{array}{l}\mathrm{LCOE} \\
(\mathrm{r}=7 \%)\end{array}$ & \\
\hline $\begin{array}{l}\text { Without } \\
\text { storage }\end{array}$ & 0.86 & 5.68 & 6.50 & $\mathrm{\Phi} / \mathrm{kWh}$ \\
\hline $\begin{array}{l}\text { With } \\
\text { storage }\end{array}$ & 0.98 & 5.17 & 5.91 & $\mathrm{\Phi} / \mathrm{kWh}$ \\
& & & &
\end{tabular}

In case TES is adopted, the capacity factor increases, as the reactor is operational at full power 24 hours every day. Storage capital costs are added at $\mathrm{t}=0$ and at the end of the TES lifetime $(\mathrm{t}=30$ years), as the TES needs to be replaced.

The adoption of the thermal storage allows the SCR capacity factor to increase, with a subsequent reduction in LCOE. The electricity production during the lifetime of the SCR was assumed constant over 60 years; however, the grid was not able to use the SCR production for three hours per day due to the peak in the CSP production. In the case without storage, SCR production was reduced, while with storage, the electricity is stored and used to produce additional electricity. In reality, LCOE for the case without the storage is believed to be higher, as overproduction may be subject to penalties.

LCOE was calculated for the CSP system with parameters shown in Table 3. The power block is sized to produce a maximum electric power of 300 MWe. With a Rankine cycle efficiency of 0.42 and a Solar Multiple (SM) of 2.4, the receiver has to be designed to produce a thermal power of about 1,714 MWth The Solar Multiple is defined as the ratio between the receiver equivalent electric power and the power block design power. Capital and operating and maintenance $(\mathrm{O} \& \mathrm{M})$ costs were mostly taken from Ref. [5], which describes cost items for a reference molten-salt power tower solar power plant. As Ref. [5] shows O\&M cost for the CSP-TES system, half of the total O\&M cost of the CSP-TES system was assumed to represent CSP O\&M cost.

Table 3. CSP parameters

\begin{tabular}{|c|c|c|}
\hline & CSP & \\
\hline Power block rating & 300 & MWe \\
\hline Solar Multiple [5] & 2.4 & - \\
\hline Rankine cycle efficiency [5] & 0.42 & - \\
\hline Receiver design thermal power & 1,714 & MWth \\
\hline $\begin{array}{ll}\text { Receiver design equivalent } \\
\text { electric power }\end{array}$ & 720 & MWe \\
\hline Life [5] & 30 & years \\
\hline Thermal storage capacity [5] & 10 & hours \\
\hline $\begin{array}{l}\text { Thermal storage equivalent } \\
\text { electric capacity }\end{array}$ & 3,000 & MWhe \\
\hline Capital costs [5] & $7,764.75$ & $\$ / \mathrm{kWe}$ \\
\hline O\&M costs (derived from [5]) & 32.5 & \$/kW-year \\
\hline $\begin{array}{l}\text { Storage O\&M costs (derived } \\
\text { from }[5,6]\end{array}$ & 2.64 & $\$ / m^{2}$-year \\
\hline O\&M costs (variable) [5] & 4 & \$/MWhe \\
\hline Storage capital cost & $\begin{array}{l}52.26 \\
19.61\end{array}$ & $\begin{array}{l}\mathrm{k} \$ / \mathrm{m}^{2} \\
\$ / \mathrm{kWh}\end{array}$ \\
\hline
\end{tabular}

For the analysis that follows, we have developed and applied simple models rather than using some of the more accurate simulation packages. The motivation was to be able to freely impose variation of parameters, examine sensitivities, and gain insight into trends and relationships, even if some effects are not accounted for. In our future work we plan to use actual detailed meteorological data rather than representative values, and properly simulate the system performance in more detail.

Meteorological data in the San Luis Valley of Colorado was used to calculate average seasonal power profiles [8]. The profiles were scaled to the power of the receiver under consideration (720 MWe equivalent). It was assumed that each day the CSP system supplies constant power to the grid. Average seasonal production profiles were considered (Fig. 2). From the power production profile, the daily constant power that the CSP is able to sustain was computed through an energy balance. For each season, it was 
assumed that the power produced by the CSP system matches the grid requirement.

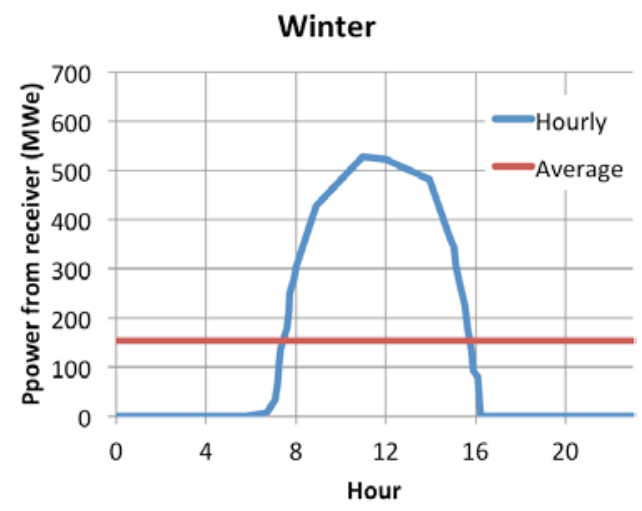

Fall - Spring

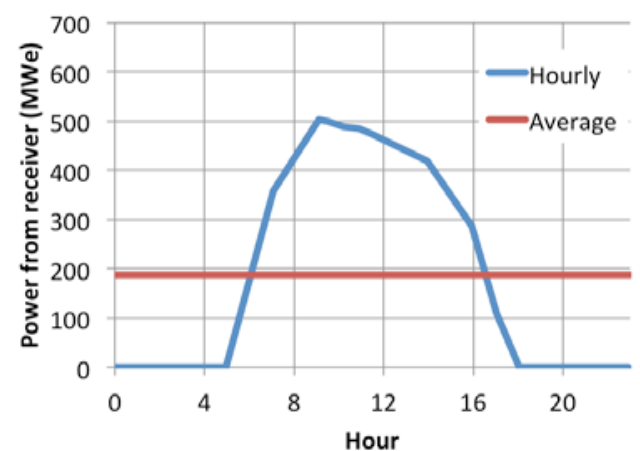

Summer

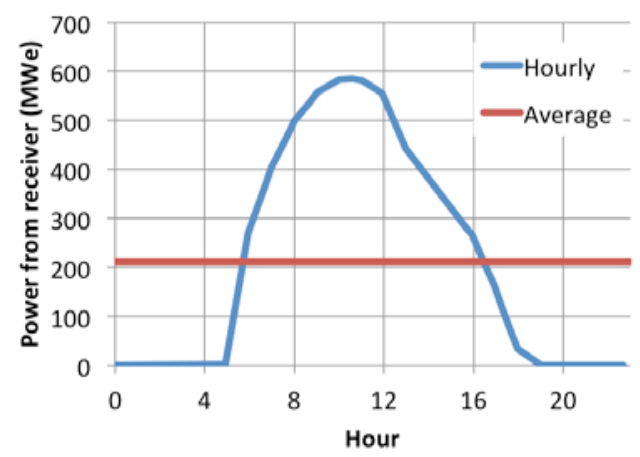

Fig. 2. - Seasonal hourly and average operating profile of the CSP plant (average day) [8]

In a more realistic case (here not simulated), as soon as the production from the field reaches the power block design power (300 MWe), the CSP system is set to produce exactly the power block design power. The excess energy is stored as thermal energy in the storage, and then used for the rest of the day to produce constant power, until the TES is emptied. This scenario, represented for the average summer day, is shown in Fig. 3.
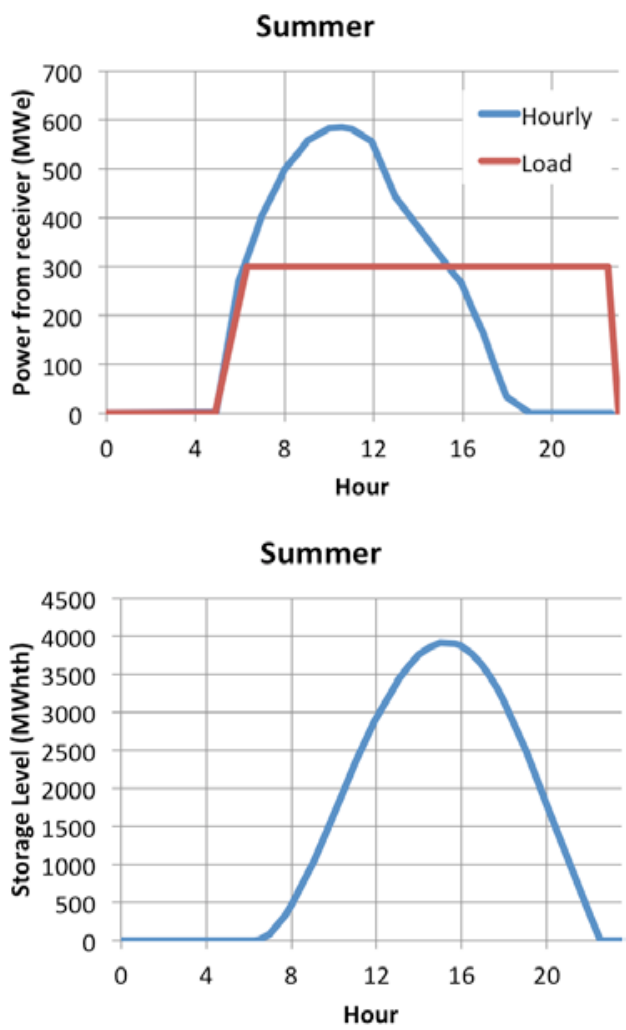

Fig. 3 -Hourly and operating profile of the CSP plant and TES (average summer day)

Capacity factors for each season, calculated with respect to the power block design power, are shown in Table 4. During the average day, when the hourly energy production is higher than the grid requirement, the surplus energy is stored in the TES. On the contrary, when the grid requirement is higher than the hourly CSP production, thermal energy is extracted from the TES and used to produce electricity. As a consequence, the quantity of energy stored in the TES (storage level) varies during the day. Storage level during the average day for each season is shown in Fig. 4. The TES capacity requirement is given by the highest TES level reached during the year. During the average summer day, the TES needs to be able to accommodate at least 5,352 MWhth, which correspond to approximately 2,248 MWhe. With a TES having this capacity, the CSP system has a full-power autonomy of 7.49 hours. Conservatively considering a TES capacity of 10 hours, LCOE is $18.56 \mathrm{\$} / \mathrm{kWh}$, with a storage contribution of 1.66 $\$ / \mathrm{kWh}(8.95 \%$ of LCOE, for $5 \%$ discount rate). Calculated LCOE for the CSP plant is shown in Table 5.

Table 4. Capacity factors

\begin{tabular}{l|l} 
& $\begin{array}{l}\text { Capacity } \\
\text { Factor }\end{array}$ \\
\hline Winter & 0.52 \\
\hline Fall-Spring & 0.62 \\
\hline Summer & 0.70 \\
\hline Average & 0.62
\end{tabular}



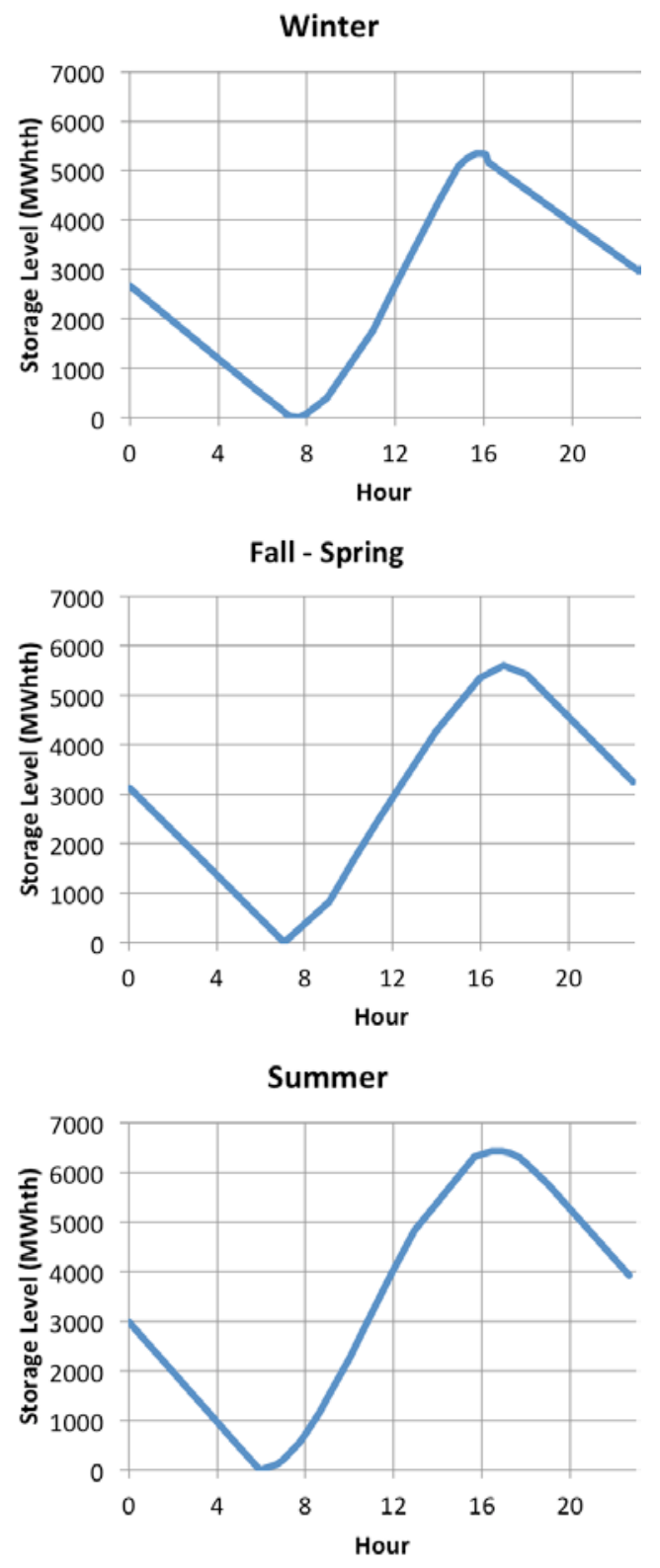

Fig. 4. - Seasonal TES level profile of the CSP plant (average day)

\section{Table 5. CSP LCOE}

\begin{tabular}{l|l|l|l} 
& LCOE & $\begin{array}{l}\text { Storage } \\
\text { cost }\end{array}$ & \\
\hline $\mathrm{r}=5 \%$ & 18.56 & $\begin{array}{l}1.66 \\
(8.95 \%)\end{array}$ & $\mathbb{\$} / \mathrm{kWh}$ \\
\hline $\mathrm{r}=7 \%$ & 22.50 & $\begin{array}{l}1.88 \\
(8.37 \%)\end{array}$ & $\mathbb{\$} / \mathrm{kWh}$
\end{tabular}

\section{Hybrid configuration}

\section{DETERMINISTIC CASE}

We first consider the CSP system together with a SCR from the combined LCOE perspective, without any design changes (i.e., still two individual systems). This reduces the CSP LCOE, while it increases the SCR LCOE. The effective average LCOE of that systems calculated with a $5 \%$ discount rate is reduced for CSP

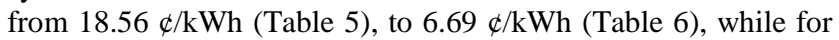
SCR with TES it is increased from $5.17 \mathrm{~d} / \mathrm{kWh}$ (Table 2) to the same $6.69 \mathrm{\&} / \mathrm{kWh} \mathrm{LCOE}$.
Table 6. Hybrid SCR-CSP LCOE (two separate 3,000 MWhe TES)

\begin{tabular}{l|l|l|l} 
& LCOE & $\begin{array}{l}\text { Storage } \\
\text { cost }\end{array}$ & \\
\hline $\mathrm{r}=5 \%$ & 6.69 & $\begin{array}{l}0.36 \\
(5.34 \%)\end{array}$ & $\mathbb{\$} / \mathrm{kWh}$ \\
\hline $\mathrm{r}=7 \%$ & 7.78 & $\begin{array}{l}0.41 \\
(5.21 \%)\end{array}$ & $\mathbb{\$} / \mathrm{kWh}$
\end{tabular}

As the two power plants are combined into a hybrid system, the two TESs can be combined into a single TES having the combined capacity. As compared to having two separate TES, the single TES configuration allows savings in capital cost and O\&M costs. In fact, these costs increase less than proportionally with the TES size, as they were modeled to be proportional to the tank surface area (Table 7).

Table 7. Hybrid SCR-CSP LCOE (shared 6,000 MWhe TES)

\begin{tabular}{l|l|l|l} 
& LCOE & $\begin{array}{l}\text { Storage } \\
\text { cost }\end{array}$ & \\
\hline $\mathrm{r}=5 \%$ & 6.62 & $\begin{array}{l}0.28 \\
(4.29 \%)\end{array}$ & $\mathbb{\$} / \mathrm{kWh}$ \\
\hline $\mathrm{r}=7 \%$ & 7.69 & $\begin{array}{l}0.32 \\
(4.18 \%)\end{array}$ & $\mathbb{\$} / \mathrm{kWh}$
\end{tabular}

The SCR and the CSP have different storage requirements characteristics, given by individual requirement probability density functions. As a consequence, as the SCR (with TES) and CSP (with TES) are combined and integrated into a hybrid configuration with a single TES, the required capacity of that single TES should be lower than the sum of the storage capacity needed for the two separate systems. That less-than-combinedcapacity common storage may provide the same level of reliability (effectiveness) as the two individual ones. A sensitivity analysis was carried out to analyze the impact of the common single TES capacity on LCOE (Fig. 5).

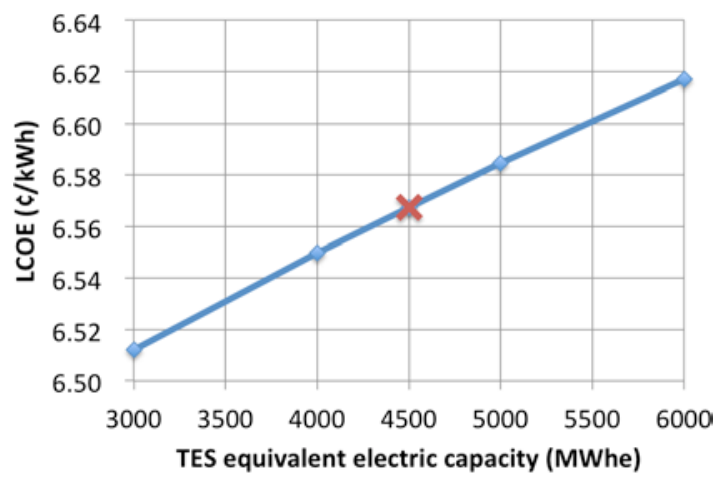

Fig. 5. - Hybrid SCR-CSP LCOE (5\% discount rate)

On the low extreme, the capacity of the shared storage would be 3,000 MWhe (if the complete sharing of the TES is possible); the LCOE (for $5 \%$ discount rate) is then $6.51 \mathrm{c} / \mathrm{kWh}$. If the required TES capacity is higher, LCOE increases and ultimately reaches the LCOE value shown in Table 7 for a single 6,000 MWhe TES (if there is no synergy in sharing the storage capacity). We note that one large TES is still cheaper than two small ones. Under realistic assumptions, the required capacity will be somewhere in between. Assuming a 4,500 MWhe required capacity, LCOE is $6.57 \$ / \mathrm{kWh}$ (Table 8). 
Table 8. Hybrid SCR-CSP LCOE (shared 4,500 MWhe TES)

\begin{tabular}{l|l|l|l} 
& LCOE & $\begin{array}{l}\text { Storage } \\
\text { cost }\end{array}$ & \\
\hline $\mathrm{r}=5 \%$ & 6.57 & $\begin{array}{l}0.23 \\
(3.57 \%)\end{array}$ & $\mathbb{\$} / \mathrm{kWh}$ \\
\hline $\mathrm{r}=7 \%$ & 7.64 & $\begin{array}{l}0.27 \\
(3.48 \%)\end{array}$ & $\$ / \mathrm{kWh}$
\end{tabular}

Shared storage brings LCOE savings to both the SCR and the CSP. Capital and O\&M costs for the 4,500 MWhe TES system can be divided evenly between the SCR and the CSP, giving LCOE values for the two single systems as shown in Table 9. As the two systems share the TES, LCOE for the SCR decreases from 5.91 $\$ / \mathrm{kWh}$ (Table 2) to $5.10 \mathrm{\$} / \mathrm{kWh}$ (Table 9), and LCOE for the CSP

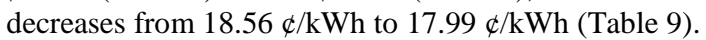

Table 9. Individual LCOE for the hybrid SCR-CSP system (shared 4,500 MWhe TES)

\begin{tabular}{|c|c|c|c|}
\hline & $\begin{array}{l}\mathrm{LCOE} \\
(\mathrm{r}=5 \%)\end{array}$ & $\begin{array}{l}\mathrm{LCOE} \\
(\mathrm{r}=7 \%)\end{array}$ & \\
\hline SCR & 5.10 & 5.84 & $\$ / \mathrm{kWh}$ \\
\hline CSP & 17.99 & 21.85 & $\mathrm{c} / \mathrm{kWh}$ \\
\hline
\end{tabular}

\section{STOCHASTIC CASE}

All analyses shown in the previous section were done for an averaged deterministic solar input and a deterministic load. In reality, TES capacities for both the SCR and the CSP are higher than the values considered in the deterministic case, because of the stochastic nature of the energy production and the grid requirements. As grid requirements, weather, and subsequently sun irradiation are variable and partly unpredictable, the TES system has to be designed to accommodate higher amounts of energy, to satisfy the high requirements of the grid with low sun irradiations. As a consequence, the systems have to be designed according to a probabilistic assessment, with the goal to accommodate a certain percentage of the load in a given time period. As TES capacity is higher, capital costs are higher and LCOE is increased.

Stochastic analyses can be performed to simulate weather conditions and grid requirements for each hour of the day in a given period of time (season, year, lifetime of the project). As proper probability distributions, production profiles, and grid profiles are used, the TES can be design so that the hybrid systems satisfy a certain percentage of the grid requirements in the given timeframe.

Preliminary analysis was carried out only considering the stochastic behavior of the weather. The weather, and subsequently the CSP production profile, was modeled under assumptions that may differ from the realistic case. The stochastic analysis was performed as a proof of concept in trying to design the optimum shared TES and demonstrate its benefit. Average production profile for each season were taken from [8] and fitted with $4^{\text {th }}$ order polynomial functions (Fig. 6).

Monte Carlo simulations were performed simulating each hour of the day and sampling the weather in each day based on the probability of sunny, partial sunny, and cloudy days in Alamosa, CO [9]. The probability, along with the average number of sunny, partial sunny, and cloudy days in a year are shown in Table 10. At the beginning of each day of the year, the weather is sampled according to the respective probabilities. As the weather is sampled, multiplicative coefficients are applied to the average CSP production profiles (Fig. 2). The coefficients are shown in Table 10. In a partial sunny day, the production profile magnitude is $70 \%$ than that of a sunny day, while in a cloudy day is $20 \%$. The coefficients are determined to preserve the average production shown in Fig. 2. Seasonal production and capacity factors (Fig. 2) were used. The grid load was assumed constant during each season. The seasonal value of the load was calculated as a sum of the average CSP production profile (Fig. 2) and the SCR electric power (1,000 MWe).

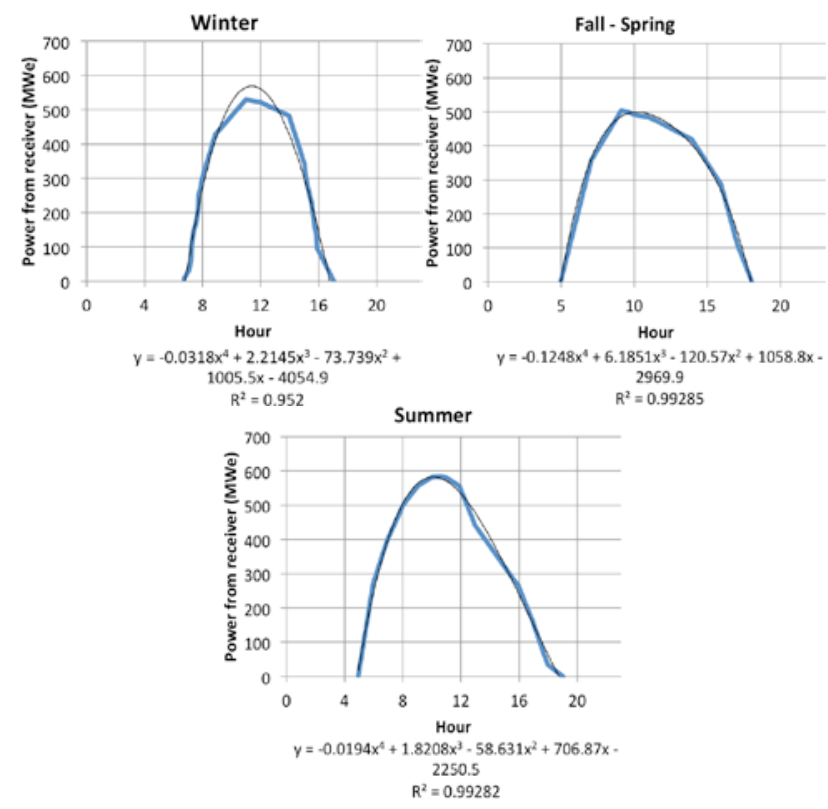

Fig. 6. - Seasonal hourly and average operating profile of the CSP plant (average day) [8], and fitted $4^{\text {th }}$ order polynomials

Table 11. Probability and average number of sunny, partial sunny, and cloudy days in Alamosa, CO [9].

\begin{tabular}{l|l|l|l} 
Weather & $\begin{array}{l}\text { Number of } \\
\text { days }\end{array}$ & Probability & $\begin{array}{l}\text { Production } \\
\text { coefficient }\end{array}$ \\
\hline Sunny & 148 & 0.4055 & 1.4043 \\
\hline Partial sunny & 137 & 0.3753 & 0.9830 \\
\hline Cloudy & 80 & 0.2192 & 0.2809
\end{tabular}

Simulating the electricity dispatch from the hybrid system during the year a sufficient amount of times, the distribution of the average percentage of the grid that is satisfied can be estimated, given a TES capacity. For each hour of the day, if the electricity production from the hybrid system is higher than the grid requirement, (average production profile) the excess energy is stored in the TES. In case the electricity production from the CSP-SCR for a given hour is lower than the grid requirements, all electricity produced by the CSP and the LSR is sent to the grid, along with the energy stored in the TES. Results of the Monte Carlo simulations are shown in Table 10.

Table 10. Monte Carlo simulations results (year sampled 1,000 times)

\begin{tabular}{l|l|l}
$\begin{array}{l}\text { TES capacity } \\
\text { (MWhe) }\end{array}$ & $\begin{array}{l}\text { \% grid energy } \\
\text { satisfied }\end{array}$ & $\begin{array}{l}\text { LCOE } \\
(\mathbb{\$} / \mathrm{kWh})\end{array}$ \\
\hline 0 & 90.68 & 6.98 \\
\hline 1500 & 95.81 & 6.73 \\
\hline 3000 & 98.11 & 6.64 \\
\hline 4500 & 98.82 & 6.65 \\
\hline 6000 & 99.19 & 6.67
\end{tabular}

As the TES capacity is increased, the percentage of the energy delivered to the grid increases. Under the assumptions used in this simulation, the minimum LCOE does in fact occur for the storage capacity of 3,000 MWhe. 


\section{Work in progress and future work}

We note that the reference power against which the total production is compared in Table 10 is based on the seasonally available insolation, not on the power block full power of 300 MWe or the actual demand. Moreover, the percentage refers to the combined CSP+SCR system, which includes the near-constant SCR production, and thus makes the variability in the CSP production, storage and utilization seem smaller. In reality, if the energy produced by the hybrid system (CSP, SCR, TES) is lower than the grid requirement, the grid is not completely satisfied. In this case, the system can be subject to a penalty that negatively impacts LCOE and the present value of the project. Also, the weather distribution data are not completely independent, which will tend to favor larger storage. Our follow-up simulation will use such more realistic assumptions to evaluate LCOE and find the optimum storage size that leads to a minimum LCOE and maximum present value of the project.

There are other synergistic effects with positive impact on LCOE to be evaluated in future analysis. For example, With the integrated system, CSP would not need auxiliary gas-fired salt heating systems for periods of bad weather, since that function would be provided by SCR. On the other hand, TES and SCP would provide a redundant power source to SCR in case of the loss of offsite power.

\section{Conclusions}

In this paper we have examined performance of the Nu-Renew, a Nuclear-renewables hybrid energy systems that can provide a pathway for accelerated deployment of the CSP technology and harmonized deployment of low-emission power sources, nuclear and renewables. We have demonstrated that combining a nuclear reactor and a CSP system in a symbiotically working nuclear-CSP hybrid system reduces the total amount of storage needed and decreases LCOE. As the storage between the two systems is shared, the storage total capital costs are lower and LCOE is reduced. Coupling the CSP-TES system with a salt cooled reactor, LCOE decreases by almost a third. Furthermore, as TES is shared by the two electricity-generating plants, the total TES capacity needed is lower than the sum of the TES capacities needed by the two individual systems. In addition to the sharing-enabled savings, the economy of scale applied to TES contributes to LCOE reduction. If the TES cost is evenly split by the CSP and the SCR, the individual LCOEs of the two systems are lower.
We have proposed a method to design storage capacity taking into account the stochastic nature of the weather and the grid. Monte Carlo simulations are performed sampling the weather and the grid requirement for each hour of the day during the lifetime of the project, based on respective probability distributions. Preliminary results considering only the stochastic weather conditions demonstrate the application of the method in designing the TES to satisfy a percentage of the grid requirement during a given period of time.

\section{References}

[1] B. Petrovic, M. Begovic, M. Brown, J. Crittenden, J.C. Santamarina, Z. Ma (NREL), "Nuclear-Renewable Energy Park NuRenew,” Proposal to NSF, 2011.

[2] B. Petrovic, "NuRenew: Hybrid Nuclear (SCR)Renewable(CSP) Energy Park," presented at the Workshop on Hybrid Energy Systems, Salt Lake City, UT, April 3-4, 2012 (HES-2012).

[3] B. Petrovic, "Nu-Renew - An Advanced Hybrid NuclearRenewable Energy Park”, ICREPQ'16, Madrid, Spain (May 2016).

[4] Projected Costs of Generating Electricity, in IEA/NEA. Paris, France (2010).

[5] C. S. Turchi, G. A. Heath, "Molten Salt Power Tower Cost Model for the System Advisor Model (SAM)", NREL/TP5500-57625, National Renewable Energy Laboratory, Golden, CO (February 2013).

[6] Ulf Herrmann, Michael Geyer, Rainer Kistner, "The AndaSol Project", Workshop on Thermal Storage for Trough Power Systems (February 2002).

[7] D. E. Holcomb, F. J. Peretz, A. L. Qualls, "Advanced High Temperature Reactor Systems and Economic Analysis," ORNL/TM-2011/364, Oak Ridge National Laboratory, Oak Ridge, TN (September 2011).

[8] J. Jorgenson, P. Denholm, M. Mehos, C. Turchi, "Estimating the Performance and Economic Value of Multiple Concentrating Solar Power Technologies in a Production Cost Model”, NREL/TP-6A20-58645, National Renewable Energy Laboratory, Golden, CO (December 2013).

[9] https://www.currentresults.com/Weather/Colorado/annualdays-of-sunshine.php 